\title{
Thermal Properties of Tristearin by Adiabatic and Differential Scanning Calorimetry
}

\author{
Marija Matovic* and J. Cees van Miltenburg
}

Faculty of Chemistry, Chemical Thermodynamics Group, Debye Institute, Utrecht University, Padualaan 8, $3584 \mathrm{CH}$ Utrecht, The Netherlands

\begin{abstract}
Jan Los
IMM Laboratory of Solid State Chemistry, Radboud University Nijmegen, Toernooiveld, 6525 ED Nijmegen, The Netherlands
\end{abstract}

\section{Francois G. Gandolfo and Eckhard Flöter}

Unilever Research \& Development, P.O. Box 114, 3130 AC Vlaardingen, The Netherlands

\begin{abstract}
The thermal behavior of tristearin was studied by adiabatic calorimetry and differential scanning calorimetry (DSC). Specific heat capacities of two polymorphic forms were measured in the adiabatic calorimeter, where the $\beta$-form was measured from $10 \mathrm{~K}$ to $370 \mathrm{~K}$ and the $\alpha$-form was measured from 175 $\mathrm{K}$ to $370 \mathrm{~K}$. The start of the measurement of the stable $\beta$-form from $10 \mathrm{~K}$ allowed the calculation of its entropy, so we report the derived values of absolute entropy for the two forms of tristearin at $298.15 \mathrm{~K}$. The enthalpies of fusion and melting temperatures for each polymorph were calculated from both the adiabatic and the DSC experimental data and are compared to the literature values. The values for the enthalpies of fusion of the stable $\beta$-form are in excellent agreement, being $(221.6 \pm 1){\mathrm{J} \cdot \mathrm{g}^{-1}}^{-1}$ and $(219.6 \pm$ 2) $\mathrm{J} \cdot \mathrm{g}^{-1}$ according to the adiabatic and DSC measurements, respectively. The data for the $\alpha$-form are not in so good agreement, which we attribute to the difficulty to crystallize this phase in its pure form. Moreover, we examined the fleeting existence of the $\beta^{\prime}$-form and its transformation to the $\beta$-phase under isothermal conditions.
\end{abstract}

\section{Introduction}

Glycerides form an important class of natural products, as they are constituents of oils and fats. A very detailed review of the thermal properties of the acylglycerides is found in the chapter written by Hagemann in the Surfactant Science Series. ${ }^{1}$ Glycerol trioctadecanoate $\left(\mathrm{C}_{57} \mathrm{H}_{110} \mathrm{O}_{6}\right)$, or tristearin for short, often indicated as SSS, is one of the saturated monoacid triglycerides and is probably the best researched triglyceride concerning thermal behavior. Despite this fact, we undertook this research as we feel that the combination of adiabatic calorimetry and DSC can give more precise data and a better insight in the crystallization processes. Moreover, the use of adiabatic calorimetry made it possible to start the measurements at such a low temperature that the absolute entropy of the stable phase could be calculated. Tristearin exhibits four polymorphic forms $\left(\alpha, \beta_{2}{ }^{\prime}, \beta_{1}{ }^{\prime}\right.$, and $\left.\beta\right)$, which have been identified by different techniques, like X-ray studies, ${ }^{2-12} \mathrm{DSC},{ }^{7-18} \mathrm{Ra}-$ man spectroscopy, ${ }^{11}$ calorimetry, ${ }^{20-22}$ and microscopy. ${ }^{23}$ In this work, we observed the existence of two $\beta^{\prime}$-forms by DSC, but the small temperature range in which the $\beta_{2}^{\prime}$ phase occurred prevented detailed measurements on this form. In previous publications, we reported on the thermal properties of trielaidin ${ }^{25}$ (or EEE) and tripalmitin ${ }^{26}$ (or PPP). This work is part of a research project aimed at the study of metastable crystallization of binary mixtures, tristearin being one of the possible constituents.

* Corresponding author e-mail: m.matovic@chem.uu.nl.

\section{Experimental Section}

Tristearin was purchased from Larodan with a stated mass fraction purity of $>99 \%$. The compound was used as received. The DSC experiments were performed with a Mettler Toledo DSC $821^{\mathrm{e}}$, equipped with an intracooler. Samples of (2 to 3 ) $\mathrm{mg}$ were used in sealed aluminum crucibles.

The adiabatic calorimeter (laboratory indication CAL8) has been described in detail before; ${ }^{27}$ a sample of about 0.5 $\mathrm{g}$ was used. We estimate from calibration experiments that the uncertainty in the heat capacity measurements is within $0.5 \%$ and that in latent heat effects, such as melting, it is about $0.2 \%$. Oxford Instruments calibrated the thermometer based on ITS-90. The measuring procedure consisted of alternating stabilization periods and heat input periods under automatic control. The re-crystallization effects occurring in tristearin are often so slow that equilibrium is not reached within a reasonable experiment time. In these cases, the enthalpy path of the vessel and the product were calculated by using the supplied electrical energy, corrected for the heat exchanged with the surroundings, as described in detail earlier. ${ }^{28}$

\section{Results and Discussion}

DSC Experiments. (a) First Melting. Tristearin, received in a solid state, was heated at a rate of $5 \mathrm{~K} \cdot \mathrm{min}^{-1}$ from the room temperature to $363 \mathrm{~K}$. One endothermic peak was observed, indicating the melting of the stable 


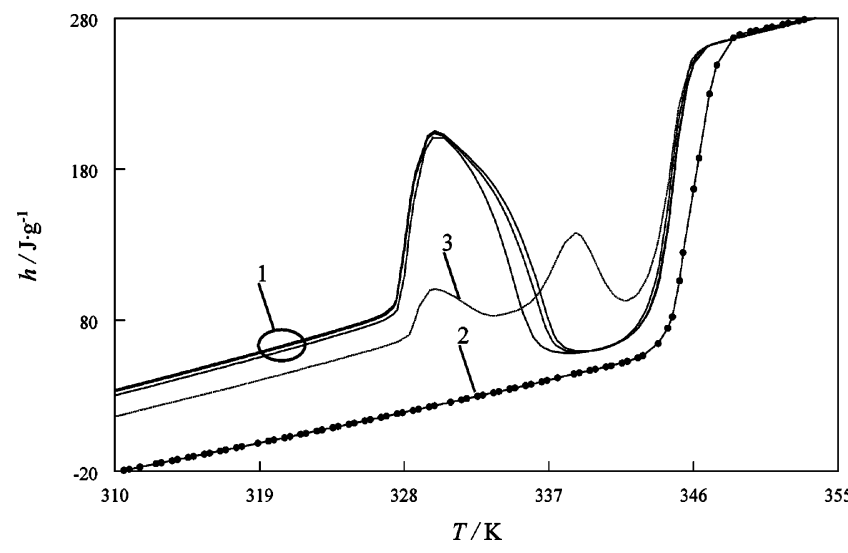

Figure 1. Pseudo-enthalpy heating curves of the solid states formed under various cooling rates. Curves 1 present the $\alpha$-polymorph formed under the cooling rates of $(-1,-5$, and -10$)$ $\mathrm{K} \cdot \mathrm{min}^{-1}$, where lower energy level corresponds to a lower cooling rate. Curves 2 and 3 represent solid states both formed under the cooling rate of $-0.1 \mathrm{~K} \cdot \mathrm{min}^{-1}$.

$\beta$-phase. The onset of melting was at $346 \mathrm{~K}$, and the enthalpy of fusion was found to be $219.6 \mathrm{~J} \cdot \mathrm{g}^{-1}$.

(b) Influence of the Cooling Rate. To examine the occurrence of the known polymorphic forms of tristearin, several sets of experiments were performed as follows: the sample was heated with the rate of $5 \mathrm{~K} \cdot \mathrm{min}^{-1}$ to (10 to 15) $\mathrm{K}$ above the melting temperature of the $\beta$-phase; subsequently in each experimental set the melt was cooled at a different rate, being $(-10,-5,-1$, and -0.1$) \mathrm{K} \cdot \mathrm{min}^{-1}$. The scanning patterns of the solid phases formed under these various cooling rates were recorded from $273 \mathrm{~K}$ at a heating rate of $5 \mathrm{~K} \cdot \mathrm{min}^{-1}$ and were transformed into pseudoenthalpy curves (presented in Figure 1). These curves are obtained by integration of the registered heat-flow signals over time and matching the enthalpy levels in the liquid phase. By applying higher cooling rates, tristearin crystallizes in the $\alpha$-polymorph which melting behavior is presented by the group of curves 1 in Figure 1 . The first endothermic effect at $327 \mathrm{~K}$ indicates the melting of the $\alpha$-form, followed by a broad exothermic peak due to the crystallization of the $\beta^{\prime}$-phase from the $\alpha$-melt. However, the $\beta^{\prime}$-phase converts readily into the $\beta$-phase that melts at the temperature lower than that reported from the melting experiment with the sample as delivered. As already noted, ${ }^{22}$ the melting temperature of the $\beta$-phase is dependent on the manner of preparation. As for the phase obtained from a melt, if rapidly prepared it exhibited a lower melting point, due to defects built in crystals of the $\beta$-phase.

Although crystallized at different cooling rates, the $\alpha$-phase always crystallized in the vicinity of $326.6 \mathrm{~K}$. The onset of melting of the $\alpha$-phase $(327 \mathrm{~K})$ coincides with this value, meaning that no significant undercooling is needed for the nucleation of the $\alpha$-form. The absence of undercooling for the $\alpha$-phase has already been discussed, ${ }^{24,29}$ while it is also observed during measurements in the adiabatic calorimeter (Figure 8, curve 1).

The curves 2 and 3 in Figure 1 present the scanning patterns of the solid forms that crystallized during cooling of the melt with the rate of $-0.1 \mathrm{~K} \cdot \mathrm{min}^{-1}$. Despite the same cooling rate, the crystallization occurred at different temperatures, resulting in different solid states. The solid phase that solidifies at $334 \mathrm{~K}$ exhibits only one endothermic peak on the scanning pattern, indicating that tristearin crystallized in the $\beta$-form upon slow cooling of the melt, as also concluded by Perron et al. ${ }^{29}$ However, the crystalliza-

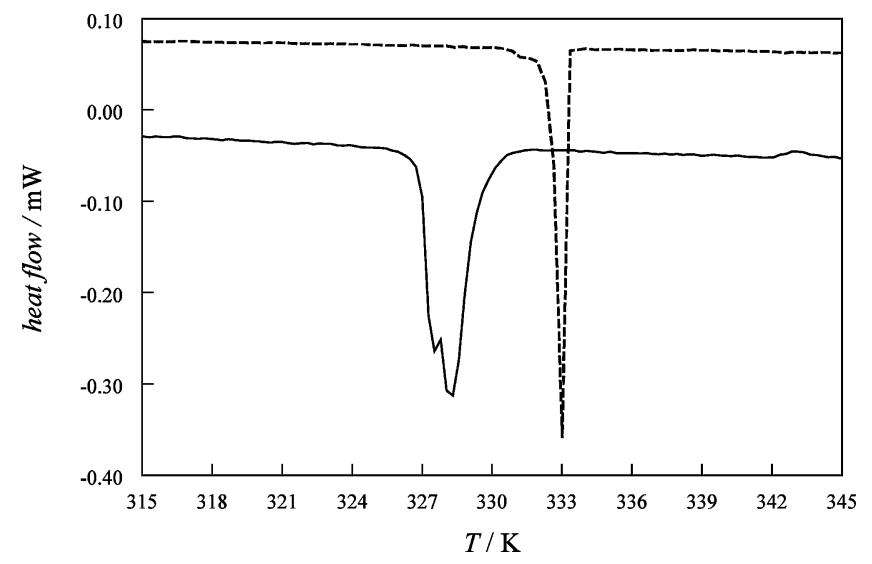

Figure 2. Crystallization of tristearin, starting at $334 \mathrm{~K}$ (dashed line) and $329 \mathrm{~K}$ (solid line) and at during the cooling of the melt with a rate of $-0.1 \mathrm{~K} \cdot \mathrm{min}^{-1}$.

tion occurred also at $329 \mathrm{~K}$ under the same cooling rate and the formed solid consisted of more than one polymorph. The scanning pattern of this solid phase (curve 3, Figure 1) demonstrates three endothermic effects, where the newly identified peak at $337.5 \mathrm{~K}$ corresponds to the melting of one of the $\beta^{\prime}$-polymorphs. We suppose that part of the melt crystallizes in one of the $\beta^{\prime}$-forms, but under constant cooling of $-0.1 \mathrm{~K} \cdot \mathrm{min}^{-1}$, the crystallization of the $\beta^{\prime}$ polymorph does not go to completion and the remaining liquid crystallizes in the $\alpha$-form.

According to Figure 2, the crystallization process that took place at $334 \mathrm{~K}$ was appreciably faster than the one occurring at $329 \mathrm{~K}$ under the same cooling rate. The nucleation rate of the $\beta$-form is very low, but once the $\beta$-nuclei are formed, instant crystallization follows. On the other hand, due to the slow nucleation kinetics of the $\beta$-form, the melt can easily be undercooled below the onset of the $\beta$-form crystallization, leading to the nucleation of the less stable polymorphs. In this case, the onset of crystallization occurred at lower temperature ( $329 \mathrm{~K})$, while the shape of recorded exothermic peak points to two-step crystallization (see Figure 2). Eventually, the final solid state consists of both the $\alpha$ - and the $\beta^{\prime}$-polymorphs.

Clearly, the influence of the applied cooling rate is evident in the final energy level of the compound. Faster cooling provides high-energy solid forms (curves 1, Figure 1 ), while slower cooling results in a lower energy state of the final solid (curves 2 and 3 ).

These observations, supported by the adiabatic measurements presented below, point to the necessity of very slow cooling of the melt in order to obtain nuclei of the $\beta$-form. They also illustrate the essential impact of kinetics on the crystallization of tristearin, which is typical for the solidification of triglycerides. The discussed influence of the cooling rate showed that principally the $\alpha$-form crystallizes when the melt is cooled fast enough, while only for very low cooling rates the crystallization of the $\beta$-form is to be expected. In between, we are left with a range of cooling rates where there is a possibility that tristearin solidifies in more than one polymorphic form.

(c) Isothermal Crystallization of Tristearin into the $\boldsymbol{\beta}^{\prime}$-Phase. Before the $\beta_{1}^{\prime}$ - and $\beta_{2}{ }^{\prime}$-forms of tristearin were identified and measured as separate phase entities, there was a discussion in the literature about the different stabilities of $\beta^{\prime}$-polymorphs for odd and even triglycerides. ${ }^{5}$ These studies indicated that the $\beta^{\prime}$-form of even triglycerides were decidedly more fleeting and thus are more difficult to characterize. 


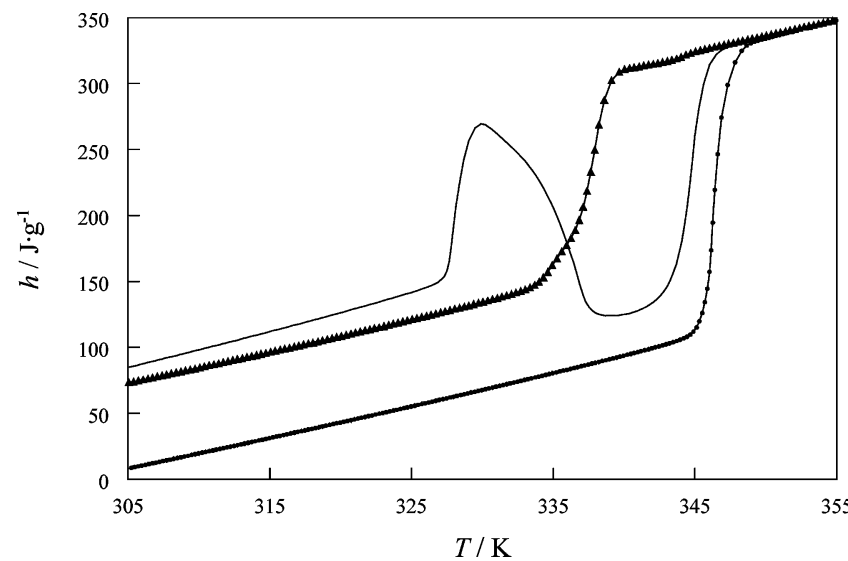

Figure 3. Pseudo-enthalpy paths of the three polymorphs of tristearin measured upon constant heating at $5 \mathrm{~K} \cdot \mathrm{min}^{-1}$ : $\alpha$-form; $\boldsymbol{\Lambda}, \beta_{2}{ }^{\prime}$-form; $\bullet, \beta$-form.

The enthalpy path of the $\alpha$-phase (Figure 1, curve 1) shows that the melting of the $\alpha$-phase is followed by the re-crystallization of the $\beta^{\prime}$-form, but the melting peak of the $\beta^{\prime}$-form could not be detected due to the interference of the $\beta^{\prime} \rightarrow \beta$ re-crystallization. Previous studies on fat crystallization ${ }^{24}$ suggested that the pure $\beta^{\prime}$-polymorph could be formed by rapid cooling of the melt to ( 1 or 2 ) $\mathrm{K}$ above the $\alpha$-melting point and stabilizing at that temperature for $30 \mathrm{~min}$ to $1 \mathrm{~h}$. Therefore, we cooled the melt using a cooling rate of $-10 \mathrm{~K} \cdot \mathrm{min}^{-1}$ to $329 \mathrm{~K}$ and left the sample at this temperature for $40 \mathrm{~min}$. After cooling the obtained solid to $273 \mathrm{~K}$, the heating was performed under a scanning rate of $5 \mathrm{~K} \cdot \mathrm{min}^{-1}$. The recorded scanning pattern corresponds to that of the $\beta_{2}^{\prime}$-form reported by Simpson and Hagemann, ${ }^{11}$ showing two endothermic peaks that indicate the melting of the $\beta_{2}^{\prime}$-phase at $334 \mathrm{~K}$ and of the $\beta_{1}^{\prime}$-phase at $338 \mathrm{~K}$. The energy level of the stable $\beta_{2}{ }^{\prime}$-form, prepared in the described way, falls between the levels of the $\alpha$ - and the $\beta$-phase, as illustrated in Figure 3 . The value for the enthalpy of fusion of the $\beta_{2}^{\prime}$-polymorph (see Table 6 ) is calculated as the difference between the extrapolated enthalpy levels of the liquid and the solid phase at the melting point of the $\beta_{2}{ }^{\prime}$-form.

However, when the $\alpha$-form was heated to the same temperature of $329 \mathrm{~K}$ and its melt left there for $40 \mathrm{~min}$, then the preparation of the $\beta^{\prime}$-form failed. On scanning the obtained solid, only one endothermic peak occurred at 345 $\mathrm{K}$, demonstrating the melting of the $\beta$-form. For comparison between the $\alpha$-melt induced crystallization and the crystallization from the undercooled melt, the heat flows registered in both cases during the isothermal crystallization at $329 \mathrm{~K}$ are given in Figure 4. Accordingly, the crystallization of the $\beta^{\prime}$-form requires no induction time when generated in the $\alpha$-melt, but it converts readily to the $\beta$-form as can be seen from the second heat effect in the relevant curve. On the other hand, the crystallization of the $\beta^{\prime}$-phase from the undercooled melt has a delay, there is a time interval during which $\beta^{\prime}$-nuclei are formed. The $\beta^{\prime}$-polymorph, obtained in such a way, does not transform so easily to the $\beta$-form. The higher stability of the $\beta^{\prime}$-form crystallized directly from the melt as compared to the one induced from the $\alpha$-melt was already reported. ${ }^{19}$

(d) Phase Stability of the $\beta^{\prime}$-Polymorph. To get more insight into the fleeting existence of the $\beta^{\prime}$-phase the following set of isothermal crystallization experiments were done at respectively $(328.15,329.15$, and 330.15) K. First the sample was heated to $373.15 \mathrm{~K}$ in order to melt it completely and to remove possible crystallization grains. Then it was cooled at a rate of $-10 \mathrm{~K} \cdot \mathrm{min}^{-1}$ to the

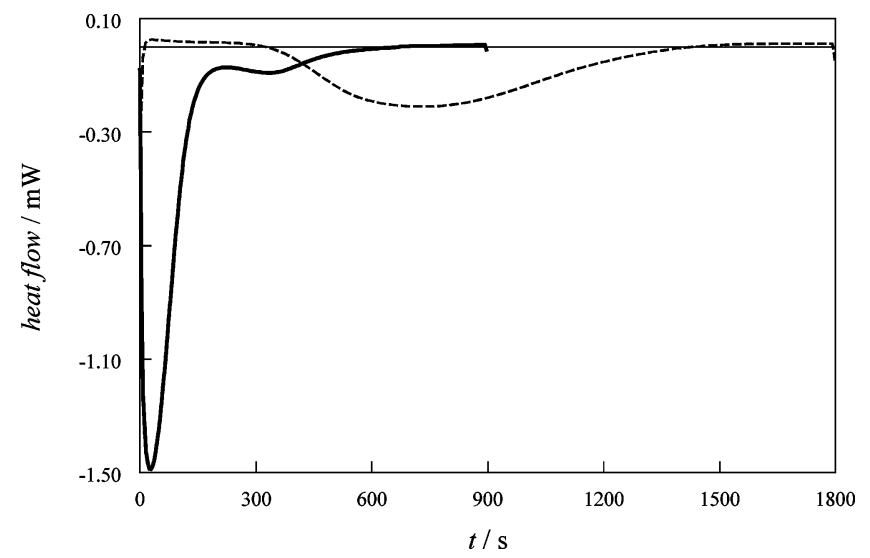

Figure 4. Isothermal crystallization of tristearin at $329 \mathrm{~K}$ from the $\alpha$-melt (solid line) and from the undercooled melt (dashed line).

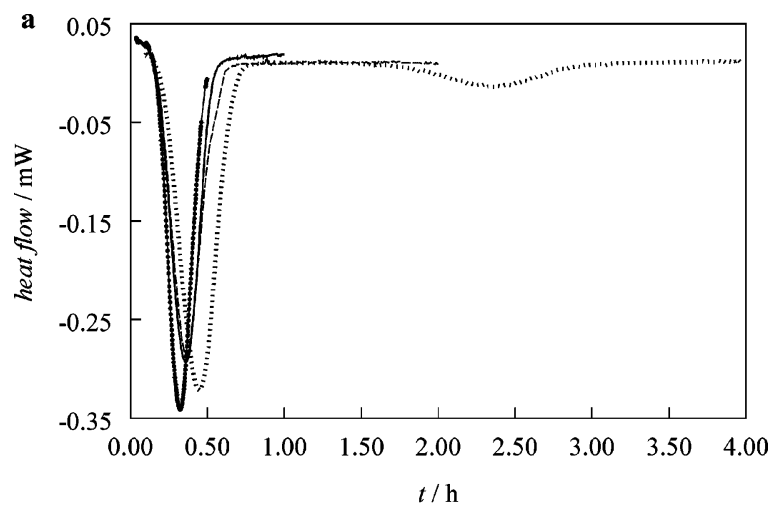

b

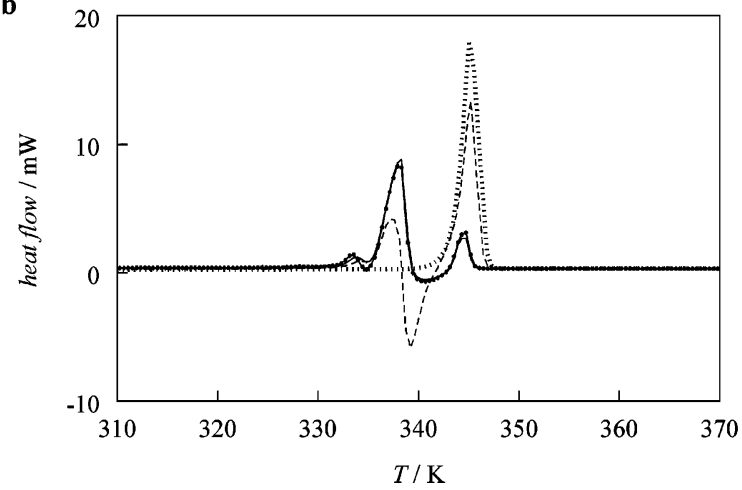

Figure 5. Isothermal crystallization of tristearin at $328.15 \mathrm{~K}$ : ๑, $30 \mathrm{~min}$; - 1 h; - - , 2 h; $\cdots, 4$ h. (Panel a) Exothermic effects registered for different stabilization period. (Panel b) Heating scans of the solids formed during the corresponding period.

stabilization temperature and kept at that temperature for respectively $30 \mathrm{~min}, 1 \mathrm{~h}, 2 \mathrm{~h}$, and $4 \mathrm{~h}$. After the stabilization period the sample was cooled to $273.15 \mathrm{~K}$ and was subsequently scanned to $373.15 \mathrm{~K}$ at a heating rate of 5 $\mathrm{K} \cdot \mathrm{min}^{-1}$. In Figures (5a,b to $\left.7 \mathrm{a}, \mathrm{b}\right)$, the results are given, where the observed exothermic heat effects during the stabilization are given in the a panels and the heating scans are given in the $\mathrm{b}$ panels. The stabilization temperatures were chosen to be above the melting/crystallization temperature of the $\alpha$-phase and below the temperature where $\beta$ crystallization was observed in the adiabatic experiments. At the chosen stabilization temperatures, there is a considerable undercooling of the $\beta$ as well as of the $\beta^{\prime}$-phase; however, in all cases the $\beta^{\prime}$-phase did crystallize first.

Typically, the crystallization of the $\beta^{\prime}$-phase from the undercooled melt was appreciably faster at lower temperatures. Indication that solidification was not complete during the isothermal period is the melting peak of the 

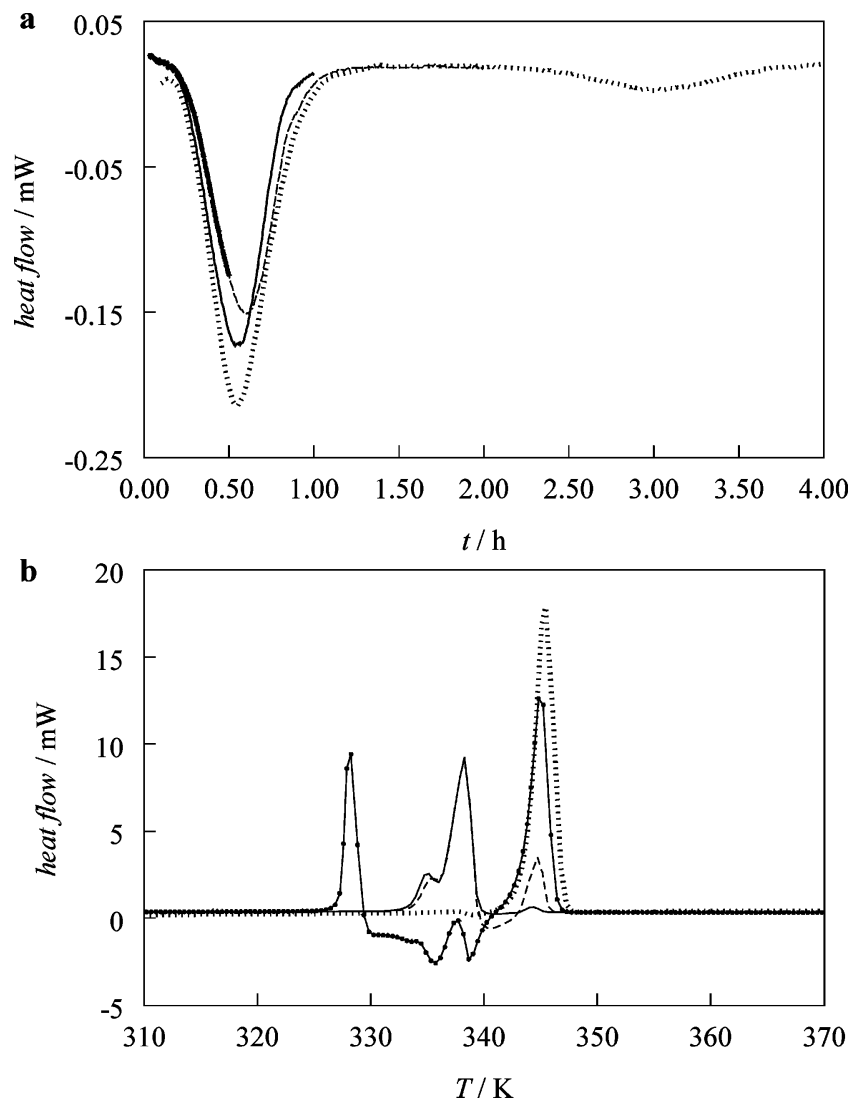

Figure 6. Isothermal crystallization of tristearin at $329.15 \mathrm{~K}$ : ๑, $30 \mathrm{~min} ;-, 1 \mathrm{~h} ;--, 2 \mathrm{~h} ; \cdots, 4 \mathrm{~h}$. (Panel a) Exothermic effects registered for different stabilization periods. (Panel b) Heating scans of the solids formed during the corresponding periods.

$\alpha$-phase that occurs on the scanning pattern. For instance, no $\alpha$-phase was observed in the solids formed at $328.15 \mathrm{~K}$ (Figure 5b), while after $30 \mathrm{~min}$ at $329.15 \mathrm{~K}$ an amount of liquid remained that solidified in the $\alpha$-phase upon cooling to $273 \mathrm{~K}$ (Figure $6 \mathrm{~b}$ ). Independently of the investigated temperatures, once the $\beta^{\prime}$-phase was formed it converted to the $\beta$-phase. However, the rate of $\beta^{\prime} \rightarrow \beta$ transition depends on the temperature, being slower at higher temperatures. The sample kept for $4 \mathrm{~h}$ at $328.15 \mathrm{~K}$ totally transformed to the $\beta$-phase, while when it was kept at $330.15 \mathrm{~K}$ for the same time some amount of the $\beta^{\prime}$-phase remained.

The stable $\beta$-phase can be prepared by very slow cooling of the liquid, as will be demonstrated in the adiabatic calorimeter experiment below, or by first forming the $\beta^{\prime}$ phase and allowing the formed solid sufficient time to transform to the $\beta$-phase. In light of very slow nucleation rate for the $\beta$-form, these observations suggest that it would be easier to prepare the most stable phase via the intermediate $\beta^{\prime}$-phase than by direct crystallization from the undercooled melt.

Adiabatic Calorimetry. (a) Crystallization from the Melt. In the adiabatic calorimeter each of the three crystalline forms studied could be crystallized from the melt. The cooling curves are shown in Figure 8, the experimental time values of the different curves were scaled in order to plot them on one axis. The scaling factor is given in the figure caption. When the sample in the adiabatic calorimeter was cooled at a rate or $16 \mathrm{~K} \cdot \mathrm{h}^{-1}$ or faster, the $\alpha$-phase crystallized. The onset of the crystallization was at $326.3 \mathrm{~K}$, remarkably no undercooling was observed (curve 1, Figure 8). This behavior is very much alike the crystallization process in long chain paraffins,
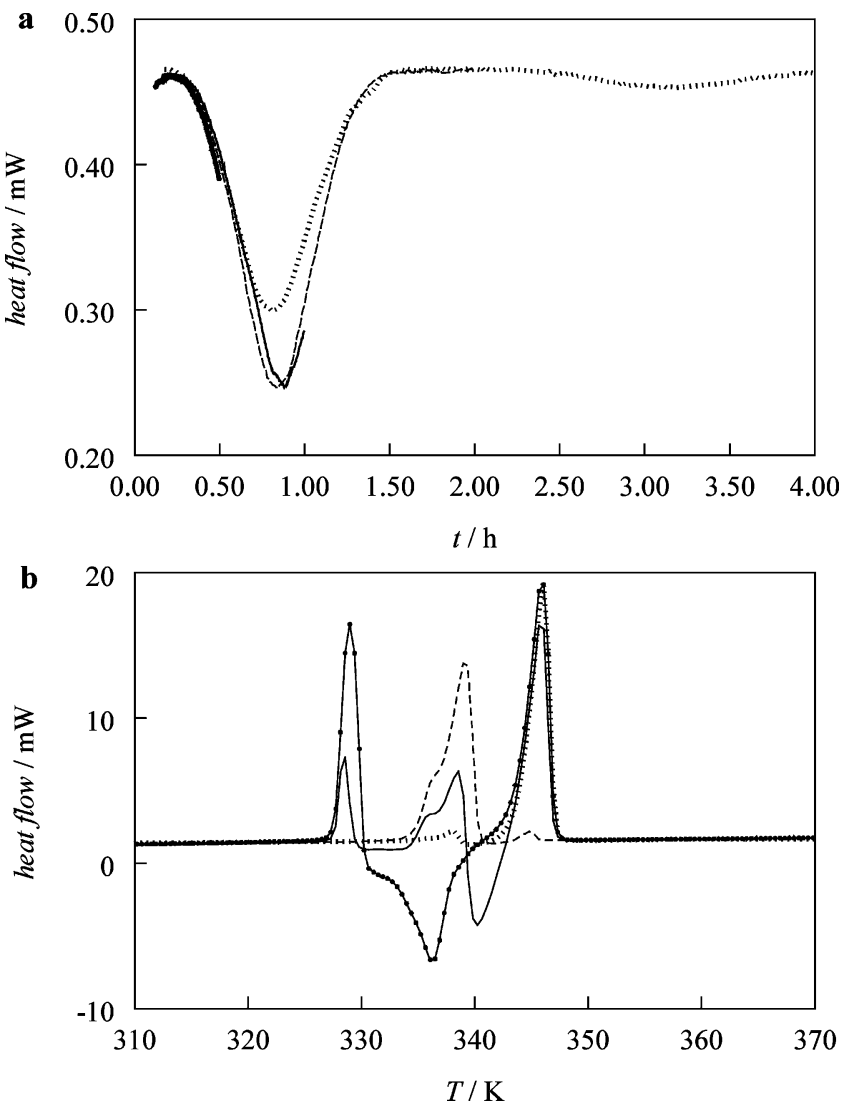

Figure 7. Isothermal crystallization of tristearin at $330.15 \mathrm{~K}$ : $\bullet, 30$ min; -, 1 h; - -, 2 h; $\cdots, 4$ h. (Panel a) Exothermic effects registered for different stabilization periods. (Panel b) Heating scans of the solids formed during the corresponding periods.

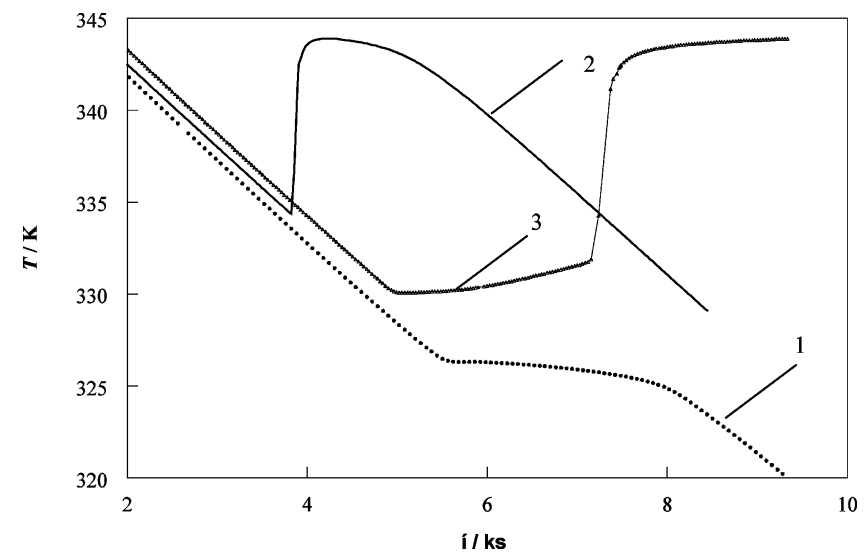

Figure 8. Cooling curves: $\bullet$, curve 1 registered upon continuous cooling at $16 \mathrm{~K} \cdot \mathrm{h}^{-1}$, leading to the formation of the $\alpha$-phase; curve 2 for cooling at $3.4 \mathrm{~K} \cdot \mathrm{h}^{-1}$, leading to crystallization of the $\beta$-phase, the time values of this curve were divided by (16/3.4) to plot it on the same scale; $\Delta$, curve 3 for cooling at $16 \mathrm{~K} \cdot \mathrm{h}^{-1}$, but stopped at $330 \mathrm{~K}$, followed by slow crystallization to the $\beta^{\prime}$-phase, at $331.9 \mathrm{~K}$ a sudden crystallization of the $\beta$-phase took place.

where the lack of undercooling is probably due to the formation of a crystalline monolayer on the surface of the liquid, a few degrees above the melting point. ${ }^{30}$ We think that a similar process is involved here. The second curve in Figure 8 was made with a cooling rate of $3.4 \mathrm{~K} \cdot \mathrm{h}^{-1}$, in this case spontaneous crystallization of the $\beta$-phase occurred at $334.4 \mathrm{~K}$. The third curve was again made at 16 $\mathrm{K} \cdot \mathrm{h}^{-1}$, but in this case adiabatic conditions were restored, and the cooling process was interrupted at $330 \mathrm{~K}$. Under the adiabatic conditions, the influx of energy from the surroundings should not result in a visible temperature 
Table 1. Experimental Heat Capacities of the Stable $\beta$-Phase from $10 \mathrm{~K}$ to $370 \mathrm{~K}$

\begin{tabular}{|c|c|c|c|c|c|c|c|}
\hline$T$ & $c_{\mathrm{p}}$ & $T$ & $c_{\mathrm{p}}$ & $T$ & $c_{\mathrm{p}}$ & $T$ & $c_{\mathrm{p}}$ \\
\hline $\mathrm{K}$ & $\mathrm{J} \cdot \mathrm{K}^{-1} \cdot \mathrm{g}^{-1}$ & $\mathrm{~K}$ & $\mathrm{~J} \cdot \mathrm{K}^{-1} \cdot \mathrm{g}^{-1}$ & $\mathrm{~K}$ & $\mathrm{~J} \cdot \mathrm{K}^{-1} \cdot \mathrm{g}^{-1}$ & $\mathrm{~K}$ & $\mathrm{~J} \cdot \mathrm{K}^{-1} \cdot \mathrm{g}^{-1}$ \\
\hline \multicolumn{2}{|c|}{ Series 1} & 30.62 & 0.176 & 143.02 & 0.830 & 283.16 & 1.520 \\
\hline 297.32 & 1.609 & \multicolumn{2}{|c|}{ Series 4} & 145.92 & 0.852 & 286.11 & 1.538 \\
\hline 298.40 & 1.611 & 30.93 & 0.168 & 148.83 & 0.863 & 289.07 & 1.556 \\
\hline 299.84 & 1.632 & 33.29 & 0.207 & 151.73 & 0.873 & 292.03 & 1.584 \\
\hline 301.82 & 1.653 & 35.42 & 0.230 & 154.64 & 0.887 & 294.99 & 1.602 \\
\hline 303.79 & 1.674 & 37.51 & 0.242 & 157.55 & 0.890 & 297.96 & 1.625 \\
\hline 305.75 & 1.692 & 39.73 & 0.252 & 160.46 & 0.918 & 300.94 & 1.645 \\
\hline 307.70 & 1.709 & 41.97 & 0.269 & 163.37 & 0.927 & \multicolumn{2}{|c|}{ Series 6} \\
\hline 309.65 & 1.723 & 44.25 & 0.295 & 166.29 & 0.940 & 304.05 & 1.670 \\
\hline 311.60 & 1.741 & 46.55 & 0.307 & 169.20 & 0.952 & 306.72 & 1.699 \\
\hline 313.55 & 1.761 & 48.96 & 0.330 & 172.12 & 0.961 & 308.94 & 1.716 \\
\hline 315.49 & 1.772 & 51.41 & 0.350 & 175.04 & 0.976 & 311.17 & 1.732 \\
\hline 317.43 & 1.793 & 53.88 & 0.373 & 177.95 & 0.985 & 313.39 & 1.751 \\
\hline 319.37 & 1.826 & 56.39 & 0.398 & 180.87 & 0.999 & 315.61 & 1.768 \\
\hline 321.32 & 1.842 & 58.93 & 0.418 & 183.79 & 1.011 & 317.83 & 1.793 \\
\hline 323.27 & 1.862 & 61.51 & 0.442 & 186.70 & 1.034 & 320.05 & 1.822 \\
\hline 325.23 & 1.887 & 64.13 & 0.466 & 189.62 & 1.053 & 322.28 & 1.846 \\
\hline 327.20 & 1.907 & 66.78 & 0.487 & 192.54 & 1.074 & 324.50 & 1.869 \\
\hline 329.17 & 1.931 & 69.45 & 0.507 & 195.45 & 1.091 & 326.72 & 1.899 \\
\hline 331.15 & 1.960 & 72.14 & 0.525 & 198.37 & 1.095 & 328.95 & 1.922 \\
\hline 3.14 & 1.988 & 4.85 & 0.543 & 201.29 & 1.119 & 331.17 & 1.953 \\
\hline 335.14 & 2.030 & 77.59 & 0.562 & 204.21 & 1.131 & 333.40 & 1.992 \\
\hline 337.14 & 2.068 & 80.34 & 0.577 & 207.13 & 1.138 & 335.63 & 2.031 \\
\hline \multicolumn{2}{|c|}{ Series 2} & 83.10 & 0.595 & 210.05 & 1.148 & 337.85 & 2.073 \\
\hline 9.65 & 0.009 & 85.88 & 0.612 & 212.96 & 1.155 & 340.08 & 2.142 \\
\hline 9.71 & 0.014 & 88.67 & 0.626 & 215.88 & 1.164 & 342.28 & 2.395 \\
\hline 10.85 & 0.025 & 91.47 & 0.642 & 218.80 & 1.172 & 344.14 & 8.560 \\
\hline 12.51 & 0.030 & \multicolumn{2}{|c|}{ Series 5} & 221.72 & 1.176 & 345.13 & 54.85 \\
\hline 13.96 & 0.037 & 85.71 & 0.606 & 224.64 & 1.186 & 345.47 & 144.88 \\
\hline 15.56 & 0.049 & 88.61 & 0.622 & 227.55 & 1.197 & 345.62 & 278.92 \\
\hline 17.30 & 0.070 & 91.44 & 0.635 & 230.47 & 1.212 & 345.71 & 439.05 \\
\hline 19.33 & 0.078 & 94.27 & 0.649 & 233.39 & 1.228 & 345.76 & 998.91 \\
\hline 21.58 & 0.092 & 97.11 & 0.657 & 236.30 & 1.242 & 345.79 & 1233.21 \\
\hline 23.86 & 0.113 & 99.95 & 0.670 & 239.22 & 1.258 & 345.86 & 285.47 \\
\hline 26.19 & 0.131 & 102.80 & 0.685 & 242.14 & 1.272 & 346.95 & 3.418 \\
\hline 28.56 & 0.154 & 105.65 & 0.687 & 245.06 & 1.289 & 349.12 & 2.211 \\
\hline 30.99 & 0.178 & 108.50 & 0.691 & 247.98 & 1.307 & 351.37 & 2.211 \\
\hline \multicolumn{2}{|c|}{ Series 3} & 111.36 & 0.704 & 250.90 & 1.321 & 353.63 & 2.216 \\
\hline 9.60 & 0.012 & 114.22 & 0.718 & 253.82 & 1.338 & 355.89 & 2.223 \\
\hline 11.58 & 0.025 & 117.09 & 0.731 & 256.74 & 1.355 & 358.16 & 2.228 \\
\hline 13.59 & 0.034 & 119.95 & 0.742 & 259.67 & 1.371 & 360.45 & 2.235 \\
\hline 15.41 & 0.044 & 122.82 & 0.753 & 262.60 & 1.389 & 362.74 & 2.241 \\
\hline 17.41 & 0.057 & 125.70 & 0.763 & 265.53 & 1.407 & 365.05 & 2.249 \\
\hline 19.45 & 0.074 & 128.58 & 0.775 & 268.46 & 1.426 & 367.37 & 2.252 \\
\hline 21.54 & 0.089 & 131.46 & 0.818 & 271.39 & 1.442 & 369.71 & 2.261 \\
\hline 23.71 & 0.110 & 134.35 & 0.818 & 274.33 & 1.460 & & \\
\hline 25.95 & 0.129 & 137.23 & 0.804 & 277.27 & 1.489 & & \\
\hline 28.25 & 0.152 & 140.13 & 0.817 & 280.21 & 1.502 & & \\
\hline
\end{tabular}

increase on the scale used in this Figure. The temperature however did slowly increase, indicating that a crystallization process took place, most probably to one of the $\beta^{\prime}$-phases. At $331.9 \mathrm{~K}$, the slow increase suddenly changed and the sample crystallized to the $\beta$-phase. Direct formation of the $\beta^{\prime}$-phase in the calorimeter was thus excluded as the crystallization process raises the temperature to a value where crystallization to the $\beta$-phase takes place.

(b) The $\boldsymbol{\beta}$-Phase. From the DSC experiment, we knew that the sample as received was in the $\beta$-form. To allow optimum relaxation of this crystal form, the sample was first heated till about $2 \mathrm{~K}$ below the melting point of the stable $\beta$-polymorph. At this temperature the sample was stabilized for $24 \mathrm{~h}$ before cooling to liquid helium temperature. In Table 1, the subsequent measurements from (10 $\mathrm{K}$ to $370 \mathrm{~K}$ ) are given. The heat capacity curves of this phase and of the other polymorphs discussed below are shown in Figure 10. Around $130 \mathrm{~K}$ a small, unexplained hump in the data is observed, we repeated the measurements in this temperature region twice with the same result. The absolute entropy $s_{\text {abs }}$ and melting enthalpy $h(T)-h(0)$ of the $\beta$-polymorph were calculated by numerical integration. The starting values of this integration were calculated at $10 \mathrm{~K}$ by assuming that below this temperature the Debye low-temperature limit for the heat capacity

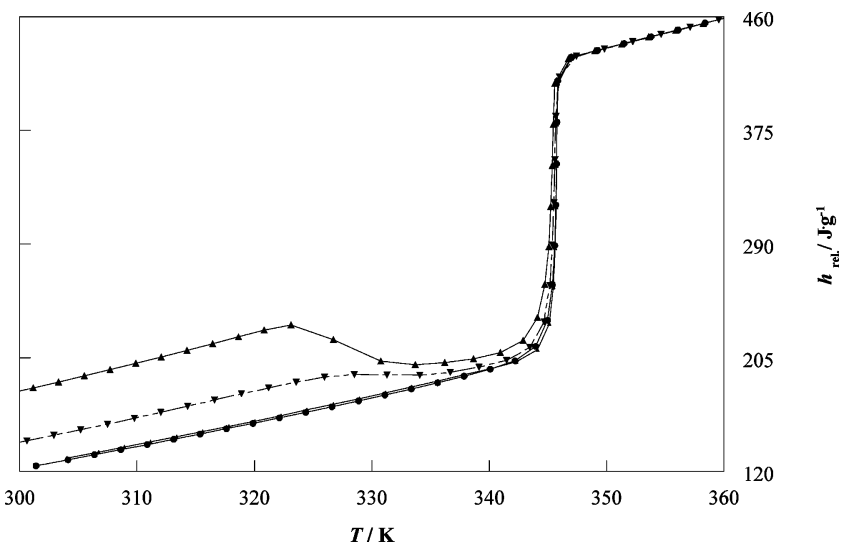

Figure 9. Experimental relative enthalpy curves: $\Delta, \alpha$-phase; $\boldsymbol{\bullet}, \beta$-phase; $\boldsymbol{\nabla}$, the solid formed by annealing the melt at $328 \mathrm{~K}$ for $4 \mathrm{~h}$. The curves are shifted so that they coincide in the liquid phase.

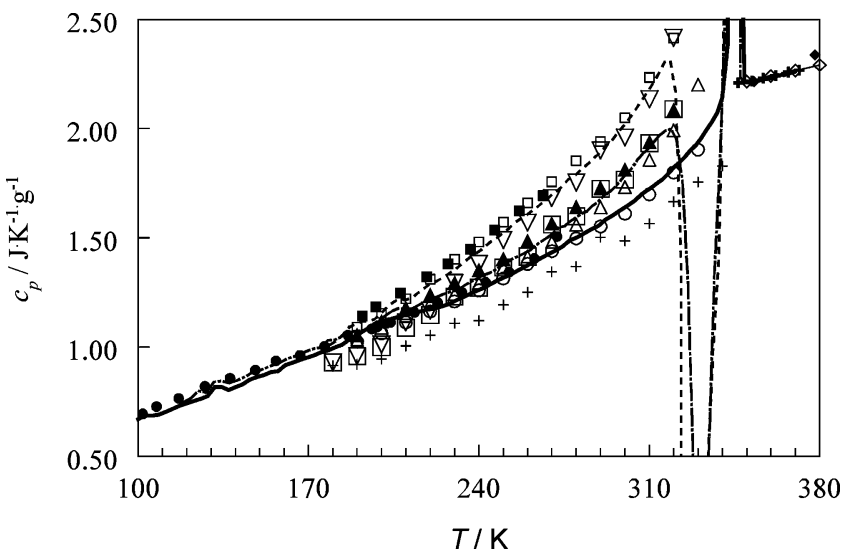

Figure 10. Comparing the experimental heat capacity curves of tristearin with literature data: $\alpha$-phase: - -, this work; $\square$, Simpson; ${ }^{17} \nabla$, Hampson and Rothbart; ${ }^{18} \mathbf{m}$, Charbonnet and Singleton. ${ }^{20}$ $\beta$-phase: - this work; $\bigcirc$, Simpson; ${ }^{17}+$, Hampson and Rothbart; ${ }^{18}$ $\bullet$, Charbonnet and Singleton. ${ }^{20} \beta^{\prime}$-phase: - - - this work; $\Delta,\left(\beta_{1}{ }^{\prime}\right)$ Simpson; ${ }^{17} \boldsymbol{\Delta},\left(\beta_{2}{ }^{\prime}\right)$ Simpson; ${ }^{17} \square$, Hampson and Rothbart. ${ }^{18}$ Liquid phase: - this work; $\diamond$, Morad et al.; ${ }^{15} \diamond$, Phillips and Mattamal; ${ }^{16}$ + , Charbonnet and Singleton ${ }^{20}$.

Table 2. Derived Thermodynamic Properties of the $\beta$-Form of Tristearin at Selected Temperatures

\begin{tabular}{|c|c|c|c|c|c|c|c|}
\hline$T$ & $c_{\mathrm{p}}$ & $s_{\text {abs }}$ & $h-h(0)$ & $T$ & $c_{\mathrm{p}}$ & $s_{\text {abs }}$ & $h-h(0)$ \\
\hline $\mathrm{K}$ & $\mathrm{J} \cdot \mathrm{K}^{-1} \cdot \mathrm{g}^{-1}$ & $\mathrm{~J} \cdot \mathrm{K}^{-1} \cdot \mathrm{g}^{-1}$ & $\mathrm{~J} \cdot \mathrm{g}^{-1}$ & $\mathrm{~K}$ & $\mathrm{~J} \cdot \mathrm{K}^{-1} \cdot \mathrm{g}^{-1}$ & $\mathrm{~J} \cdot \mathrm{K}^{-1} \cdot \mathrm{g}^{-1}$ & $\mathrm{~J} \cdot \mathrm{g}^{-1}$ \\
\hline 10 & 0.019 & 0.006 & 0.05 & 200 & 1.109 & 1.154 & 120.7 \\
\hline 20 & 0.068 & 0.036 & 0.50 & 210 & 1.148 & 1.209 & 132.0 \\
\hline 30 & 0.170 & 0.084 & 1.72 & 220 & 1.174 & 1.263 & 143.6 \\
\hline 40 & 0.254 & 0.146 & 3.91 & 230 & 1.210 & 1.316 & 155.5 \\
\hline 50 & 0.338 & 0.212 & 6.88 & 240 & 1.262 & 1.368 & 167.8 \\
\hline 60 & 0.428 & 0.282 & 10.71 & 250 & 1.317 & 1.421 & 180.7 \\
\hline 70 & 0.510 & 0.354 & 15.43 & 260 & 1.373 & 1.474 & 194.2 \\
\hline 80 & 0.575 & 0.427 & 20.87 & 270 & 1.434 & 1.527 & 208.2 \\
\hline 90 & 0.628 & 0.498 & 26.90 & 280 & 1.501 & 1.580 & 222.9 \\
\hline 100 & 0.671 & 0.566 & 33.39 & 290 & 1.564 & 1.634 & 238.2 \\
\hline 110 & 0.697 & 0.631 & 40.25 & 298.15 & 1.626 & 1.678 & 251.2 \\
\hline 120 & 0.743 & 0.694 & 47.46 & 300 & 1.639 & 1.688 & 254.2 \\
\hline 130 & 0.796 & 0.755 & 55.08 & 310 & 1.724 & 1.743 & 271.0 \\
\hline 140 & 0.817 & 0.815 & 63.21 & 320 & 1.821 & 1.799 & 288.7 \\
\hline 150 & 0.867 & 0.873 & 71.64 & 330 & 1.935 & 1.857 & 307.5 \\
\hline 160 & 0.915 & 0.931 & 80.50 & 340 & 2.140 & 1.917 & 327.7 \\
\hline 170 & 0.955 & 0.987 & 89.84 & 350 & 2.211 & 2.612 & 567.7 \\
\hline 180 & 0.994 & 1.043 & 99.58 & 360 & 2.233 & 2.675 & 589.9 \\
\hline
\end{tabular}

$\begin{array}{llll}190 & 1.056 & 1.098 & 109.8\end{array}$

could be applied. The thermodynamic functions are given in Table 2 at selected temperatures. The enthalpy of fusion of the $\beta$-phase was measured twice; the mean value was $(221.6 \pm 1) \mathrm{J} \cdot \mathrm{g}^{-1}$, and the triple point value was found to be $(345.94 \pm 0.01) \mathrm{K}$. In Table 3, the results of the two melting experiments are given, together with the linear fits 
Table 3. Melting of the $\beta$-Phase of Tristearin

\begin{tabular}{|c|c|c|}
\hline used linear functions of heat capacity & $\begin{array}{l}\text { temperature } \\
\text { interval } \\
\end{array}$ & $\Delta h_{\text {fus }}$ \\
\hline $\mathrm{J} \cdot \mathrm{K}^{-1} \cdot \mathrm{g}^{-1}$ & $\mathrm{~K}$ & $\mathrm{~J} \cdot \mathrm{g}^{-1}$ \\
\hline $\begin{array}{l}c_{\mathrm{p}}(\text { solid, } 300 \mathrm{~K}-317 \mathrm{~K})=-0.664+0.00768 \mathrm{~T} / \mathrm{K} \\
c_{\mathrm{p}}(\text { liquid, } 350 \mathrm{~K}-365 \mathrm{~K})=1.264+0.00267 \mathrm{~T} / \mathrm{K} \\
\text { mean value }\end{array}$ & 317 to 349 & $\begin{array}{l}220.9 \text { (first melt) } \\
222.4 \text { (second melt) } \\
221.6 \pm 1\end{array}$ \\
\hline
\end{tabular}

Table 4. Experimental Heat Capacities and Enthalpy Increment of the $\alpha$-Phase of Tristearin

\begin{tabular}{|c|c|c|c|c|c|}
\hline$T$ & $c_{\mathrm{p}}$ & $h(\mathrm{~T})-h(0)$ & $T$ & $c_{\mathrm{p}}$ & $h(\mathrm{~T})-h(0)$ \\
\hline $\mathrm{K}$ & $\mathrm{J} \cdot \mathrm{K}^{-1} \cdot \mathrm{g}^{-1}$ & $\mathrm{~J} \cdot \mathrm{g}^{-1}$ & K & $\mathrm{J} \cdot \mathrm{K}^{-1} \cdot \mathrm{g}^{-1}$ & $\mathrm{~J} \cdot \mathrm{g}^{-1}$ \\
\hline 178.91 & 1.010 & 134.09 & 283.59 & 1.828 & 279.67 \\
\hline 181.60 & 1.030 & 136.87 & 285.80 & 1.848 & 283.72 \\
\hline 184.26 & 1.057 & 139.63 & 288.00 & 1.874 & 287.82 \\
\hline 186.88 & 1.093 & 142.40 & 290.20 & 1.895 & 291.96 \\
\hline 189.48 & 1.106 & 145.24 & 292.39 & 1.925 & 296.15 \\
\hline 192.06 & 1.117 & 148.11 & 294.59 & 1.944 & 300.40 \\
\hline 194.63 & 1.120 & 150.99 & 296.78 & 1.978 & 304.70 \\
\hline 197.18 & 1.128 & 153.86 & 298.97 & 2.005 & 309.06 \\
\hline 199.71 & 1.155 & 156.75 & 301.16 & 2.037 & 313.47 \\
\hline 202.23 & 1.182 & 159.69 & 303.34 & 2.069 & 317.97 \\
\hline 204.74 & 1.205 & 162.68 & 305.53 & 2.106 & 322.53 \\
\hline 207.23 & 1.222 & 165.70 & 307.71 & 2.142 & 327.16 \\
\hline 209.71 & 1.215 & 168.72 & 309.89 & 2.179 & 331.88 \\
\hline 212.17 & 1.224 & 171.72 & 312.07 & 2.217 & 336.66 \\
\hline 214.62 & 1.246 & 174.75 & 314.26 & 2.259 & 341.54 \\
\hline 217.06 & 1.265 & 177.81 & 316.44 & 2.307 & 346.52 \\
\hline 219.48 & 1.287 & 180.90 & 318.63 & 2.316 & 351.60 \\
\hline 221.90 & 1.298 & 184.02 & 320.84 & 2.169 & 356.55 \\
\hline 224.30 & 1.313 & 187.15 & 323.13 & 1.384 & 360.60 \\
\hline 226.69 & 1.330 & 190.31 & 326.73 & -5.225 & 349.59 \\
\hline 229.06 & 1.347 & 193.49 & 330.77 & -2.092 & 333.57 \\
\hline 231.43 & 1.366 & 196.70 & 333.70 & 0.373 & 330.65 \\
\hline 233.79 & 1.389 & 199.94 & 336.23 & 0.983 & 332.35 \\
\hline 236.13 & 1.409 & 203.22 & 338.66 & 1.437 & 335.29 \\
\hline 238.46 & 1.426 & 206.53 & 340.96 & 2.653 & 339.93 \\
\hline 240.79 & 1.445 & 209.86 & 342.89 & 7.391 & 348.96 \\
\hline 243.10 & 1.467 & 213.23 & 344.13 & 26.47 & 366.17 \\
\hline 245.41 & 1.489 & 216.64 & 344.75 & 66.64 & 390.88 \\
\hline 247.71 & 1.503 & 220.08 & 345.07 & 126.87 & 419.16 \\
\hline 250.00 & 1.524 & 223.54 & 345.26 & 210.24 & 449.01 \\
\hline 252.28 & 1.544 & 227.04 & 345.38 & 312.73 & 479.63 \\
\hline 254.56 & 1.568 & 230.58 & 345.47 & 400.99 & 510.65 \\
\hline 256.83 & 1.585 & 234.16 & 345.60 & 167.56 & 541.20 \\
\hline 259.09 & 1.600 & 237.76 & 346.77 & 3.134 & 559.55 \\
\hline 261.34 & 1.620 & 241.39 & 349.01 & 2.220 & 565.50 \\
\hline 263.59 & 1.639 & 245.05 & 351.31 & 2.208 & 570.59 \\
\hline 265.83 & 1.659 & 248.75 & 353.61 & 2.212 & 575.66 \\
\hline 268.07 & 1.677 & 252.47 & 355.92 & 2.218 & 580.78 \\
\hline 270.30 & 1.700 & 256.24 & 358.24 & 2.223 & 585.93 \\
\hline 272.53 & 1.719 & 260.05 & 360.57 & 2.230 & 591.12 \\
\hline 274.75 & 1.742 & 263.89 & 362.91 & 2.241 & 596.35 \\
\hline 276.96 & 1.770 & 267.78 & 365.27 & 2.244 & 601.64 \\
\hline 279.18 & 1.784 & 271.70 & 367.64 & 2.250 & 606.95 \\
\hline 281.39 & 1.806 & 275.67 & 370.02 & 2.257 & 612.32 \\
\hline
\end{tabular}

of the heat capacity of the solid and the liquid phase around the melt used in the calculation. From the plot of the equilibrium temperatures in the melt against the reciprocal of the melted fraction, the purity of the sample was calculated to be $(97.9 \pm 0.1) \mathrm{mol} \%$.

(c) The $\alpha$-Phase. Cooling the sample from the liquid phase at a rate of $16 \mathrm{~K} \cdot \mathrm{h}^{-1}$ or larger resulted in the formation of the $\alpha$-phase. On heating the obtained solid from $175 \mathrm{~K}$, the heat capacity of the $\alpha$-phase is measured and the transition of $\alpha \rightarrow \beta \rightarrow$ liquid is observed. The experimental heat capacity data are given in Table 4. As in the measured temperature range exothermic effects occurred due to re-crystallization, we did include the relative enthalpy values in this table. The enthalpy values of the measuring set starting in the $\alpha$-phase were shifted, so that they coincide in the liquid phase with the enthalpy values of the liquid phase obtained from the measurement of the stable $\beta$-phase. As can be seen in Figure 10, the heat capacity of the $\alpha$-phase increases rather sharply before the melting point. In the adiabatic calorimetry experiments the transition of the $\alpha$-phase to the $\beta$-phase or the $\beta^{\prime}$-phase started already before the melting point of the $\alpha$-phase was reached. At the melting temperature of the $\alpha$-phase, being $326.6 \mathrm{~K}$ according to the DSC experiments, the formed liquid is directly transformed to the $\beta$ - or the $\beta^{\prime}$-phase. In Figure 9 the relative enthalpy curves of the different phases are given. From this picture it is clear that within the experimental time used, the transition to the $\beta$-phase was not completed, and it is only at the very end of the melting process of the $\beta$-phase that the curves coincide.

(d) The $\boldsymbol{\beta}^{\prime}$-Phase. The results from the isothermal experiments in the DSC explain why in the adiabatic calorimeter experiments the $\beta^{\prime}$-phase could not be observed. These adiabatic measurements are so slow that the sample has transformed to the $\beta$-phase before the melting point of the $\beta^{\prime}$-phase was reached. To measure the $\beta^{\prime}$-phase in the adiabatic calorimeter, we removed the vessel from the calorimeter, immersed it in hot water to melt the contents and transferred it to a temperature regulated block. The vessel was kept at $328 \mathrm{~K}$ for $4 \mathrm{~h}$, then cooled to room temperature and replaced in the calorimeter.

Although the DSC experiments showed that after $4 \mathrm{~h}$ the whole sample would convert to the $\beta$-phase, hereby we point to the essential influence of the mass of tristearin that is annealed in order to obtain the $\beta^{\prime}$-form. The whole amount of the sample of $1.55 \mathrm{mg}$ in the DSC experiment would crystallize in the $\beta_{2}{ }^{\prime}$-form within $40 \mathrm{~min}$ at $328 \mathrm{~K}$, but it transformed to the $\beta$-phase while staying at the given temperature for $4 \mathrm{~h}$. The $\beta_{2}^{\prime}$-phase, for which the heat capacity is shown in Figure 10,11 was formed in a capillary tube by annealing the melt at $328 \mathrm{~K}$ for $15-25 \mathrm{~min}$. Hence, the optimal annealing time for obtaining the pure $\beta^{\prime}$-form depends on a sample size.

The heat capacity of the solid formed outside the calorimeter is presented in Figure 10. The values are intermediate to the curves for the $\alpha$ - and the $\beta$-phase, but we cannot be sure whether it is due to the formation of the pure $\beta^{\prime}$-phase or if the measured solid was actually a mixture of the $\alpha$-phase and one or two of the other polymorphs. We believe that the $\alpha$-phase is present as the re-crystallization starts at the melting temperature of the $\alpha$-phase (see Figure 10). More detailed characterization of the solid structure is not possible by using only thermal analysis, thus we cannot give reliable heat capacity values for the $\beta^{\prime}$-phase.

(e) Enthalpy and Entropy Values of the $\alpha$ - and the $\boldsymbol{\beta}$-Phase at 298.15 K. The enthalpy and entropy values of the different polymorphic phases can be calculated by constructing a reversible path connected to the liquid phase. First the enthalpy of the liquid phase was extrapolated to the melting point of the $\alpha$-phase by assuming that the heat capacity could be extrapolated linearly. The enthalpy of fusion of the $\alpha$-phase was taken as the difference between the extrapolated enthalpy values of the liquid and the relevant solid at the melting point. Then the same procedure was repeated for the entropy, using 
Table 5. Enthalpy, Entropy, and Relative Gibbs Energy Values at 298.15 K for the Two Polymorphic Forms and the Temperatures of Fusion and the Enthalpy of Fusion

\begin{tabular}{|c|c|c|c|c|c|}
\hline & $T_{\text {fus }}$ & $\Delta h_{\text {fus }}$ & $h(298.15)-h(0)$ & $s_{\text {abs }}$ & $\mathrm{g}$ \\
\hline phase & $\mathrm{K}$ & $\overline{\mathrm{J} \cdot \mathrm{g}^{-1}}$ & $\mathrm{~J} \cdot \mathrm{g}^{-1}$ & $\overline{\mathrm{J} \cdot \mathrm{K}^{-1} \cdot \mathrm{g}^{-1}}$ & $\mathrm{~J} \cdot \mathrm{g}^{-1}$ \\
\hline$\beta$ & 345.9 & 221.6 & 251.2 & 1.678 & -249.1 \\
\hline$\alpha$ & 327.3 & 144.8 & 307.4 & 1.816 & -234.0 \\
\hline
\end{tabular}

Table 6. Melting Temperatures and Enthalpies of Fusion of the Three Polymorphic Phases and Comparison with the Literature

\begin{tabular}{|c|c|c|c|c|c|c|}
\hline \multicolumn{2}{|c|}{$\beta$} & \multicolumn{2}{|c|}{$\beta_{2}^{\prime}$} & \multicolumn{2}{|c|}{$\alpha$} & \multirow[b]{3}{*}{ reference } \\
\hline$T_{\text {fus }}$ & $\Delta h_{\text {fus }}$ & $T_{\text {fus }}$ & $\Delta h_{\text {fus }}$ & $T_{\text {fus }}$ & $\Delta h_{\text {fus }}$ & \\
\hline $\mathrm{K}$ & $\overline{J \cdot g^{-1}}$ & K & $\overline{\mathrm{J} \cdot \mathrm{g}^{-1}}$ & $\mathrm{~K}$ & $\overline{\mathrm{J} \cdot \mathrm{g}^{-1}}$ & \\
\hline 345.9 & 221.6 & & & 327.3 & 144.8 & $\begin{array}{l}\text { this work } \\
\text { adiabatic }\end{array}$ \\
\hline 346.0 & 219.6 & 336.7 & 154.2 & 327.3 & 128.0 & DSC \\
\hline 346.6 & 214.7 & 336.4 & & 328.1 & & 2 \\
\hline 344.6 & & & & 327.6 & & 3 \\
\hline 346.1 & & 337.1 & & 327.3 & & 4 \\
\hline 345.6 & & 337.6 & & 327.6 & & 7 \\
\hline 346.7 & & 336.1 & & 327.8 & & 8 \\
\hline & & 336.4 & 162.7 & & & 12 \\
\hline 346.3 & 220.7 & 337.1 & 178.4 & 327.1 & 162.9 & 14 \\
\hline 343.1 & & & & & & 15 \\
\hline & 70.4 & & & & & 19 \\
\hline 345.7 & 228.0 & & & 327.1 & 162.8 & 20 \\
\hline 345.5 & 213.0 & & & 326.0 & 153.6 & 21 \\
\hline 346.3 & 211.4 & 336.7 & 168.9 & 328.3 & 122.6 & 22 \\
\hline 345.7 & 216.7 & 337.5 & $175.2^{a}$ & 327.9 & 126.9 & 24 \\
\hline
\end{tabular}

${ }^{a}$ Not indicated in the reference for which the $\beta^{\prime}$ polymorph value is given.

as the entropy of fusion the calculated enthalpy of fusion divided by the temperature of fusion. In Table 5 , the calculated enthalpy and entropy values of the $\alpha$ - and the $\beta$-phase at $298.15 \mathrm{~K}$ are given, together with the calculated enthalpies of fusion.

(f) Comparing the Results. In Figure 10, the literature data for the heat capacities of the different phases are plotted. Generally the correspondence is good, especially for the liquid phase. However, the results of Hampson and Rothbart ${ }^{18}$ significantly deviate from our data, which could be due to the relatively high heating rate of $10 \mathrm{~K} \cdot \mathrm{min}^{-1}$ that they used for scanning solids in the DSC. In Table 6, we compare the temperatures and enthalpies of fusion of the different phases with the literature values. Here, the correspondence is also within the error margins, except for ref 19 . We think that in that case the authors integrated the DSC melting curve in the melt of the $\beta$-phase without taking into account the re-crystallization, which took place in the same run. The heat capacities of the solid formed by annealing of the melt for $4 \mathrm{~h}$ at $328 \mathrm{~K}$, obtained from the adiabatic measurement, are plotted in Figure 10. They correspond quite well to the literature data of the $\beta^{\prime}$-form. Nevertheless, we do not exclude the possibility that the relevant solid phase could be the mixture of more polymorphs in such a ratio that the heat capacity values coincide with that of the $\beta^{\prime}$-phase.

\section{Literature Cited}

(1) Hagemann, J. W. Thermal behaviour and polymorphism of acylglycerides. Crystallization and Polymorphism of Fats and Fatty Acids; Garti, N., Sato, K., Eds.; Surfactant Science Series 31; Marcel Dekker: New York, 1988; pp 9-95.

(2) Kodali, R. D.; Atkinson, D.; Redgrave, T. G. Small, D. M. Structure and polymorphism of 18-carbon fatty acyl triacylglycerols: effect of unsaturation and substitution in the 2-position. J. Lipid Res. 1987, 28, 403-413.

(3) Clarkson, C. E.; Malkin, T. Alternation in long-chain compounds. Part II. An X-ray and thermal investigation of the triglycerides. J. Chem. Soc. 1934, 666-671.
(4) Lutton, E. S. Phase behavior of triglyceride mixtures involving primarily tristearin, 2-oleyldistearin and triolein. J. Am. Oil Chem. Soc. 1955, 32, 49-53.

(5) Lutton, E. S.; Fehl, A. J. The polymorphism of odd and even saturated single acid triglycerides $\mathrm{C}_{8}-\mathrm{C}_{22}$. Lipids 1970, 5 (1), 90-99.

(6) Cebula, D. J.; Smith, P. R. Dynamic polymorphic phase transitions in a model binary triglyceride system measured by positionsensitive X-ray diffraction methods. J. Am. Oil Chem. Soc. 1990 $67,811-814$.

(7) Lavigne, F.; Bourgaux, C.; Ollivon, M. Phase transitions of saturated triglycerides. J. Phys. IV, Proc. 1993, 3, 137-140.

(8) Whittam, J. H.; Rosano, H. L. Physical aging of even saturated monoacid triglycerides. J. Am. Oil Chem. Soc. 1975, 128-133.

(9) Hagemann, J. W.; Rothfus, J. A. Polymorphism and transformation energetics of saturated monoacid triglycerides from differential scanning calorimetry and theoretical modeling. J. Am. Oil Chem. Soc. 1983, 60, 1123-1131.

(10) Oh, J. H.; McCurdy, A. R.; Clark, S.; Swanson, B. G. Characterization and thermal stability of polymorphic forms of synthesized tristearin. J. Food Sci. 2002, 67, 2911-2917.

(11) Simpson, T. D.; Hagemann, J. W. Evidence of two $\beta^{\prime}$ phases in tristearin. J. Am. Oil Chem. Soc. 1982, 59, 169-171.

(12) Kellens, M.; Reynaers, H. Study of the polymorphism of saturated monoacid triglycerides. II: polymorphic behaviour of a 50/50 mixture of tripalmitin and tristearin. Fat Sci. Technol. 1992, 94 (8), 286-293

(13) Walker, W. W. Aging of tristearin: comparison of DSC and positron lifetime results. J. Am. Oil Chem. Soc. 1987, 5, 754-756.

(14) Perron, R. R. Commentaires sur le comportement thermique des triglycerides-role de l'insaturation. Rev. Fr. Corps Gras 1984, $171-179$.

(15) Morad, N. A.; Idrees, M.; Hasan, A. A. Specific heat capacities of pure triglycerides by heat-flux differential scanning calorimetry. J. Therm. Anal. 1995, 45, 1449-1461.

(16) Phillips, J. C.; Mattamal, M. M. Correlation of liquid heat capacities for the carboxylic esters. J. Chem. Eng. Data 1976,21, $228-232$

(17) Simpson, T. D. Specific heats of the solid-state phases of trimargarin and tristearin. J. Am. Oil Chem. Soc. 1984, 61 (5), 883886.

(18) Hampson, J. W.; Rothbart H. L. Triglyceride specific heat determined by differential scanning calorimetry. J. Am. Oil Chem. Soc. 1983, 60, 1102-1104.

(19) Desmedt, A.; Culot, C.; Deroanne, C.; Durant, F.; Gibon, V. Influence of cis and trans double bonds on the thermal and structural properties of monoacid triglycerides. J. Am. Oil Chem. Soc. 1990, 67, 658-660.

(20) Charbonnet, G. H.; Singleton, W. S. Thermal properties of fats and oils. J. Am. Oil Chem. Soc. 1947, 140-142.

(21) Norton, I. T.; Lee-Tuffnell, C. D.; Ablett, S.; Bociek, S. M. A calorimetric, NMR and X-ray diffraction study of the melting behavior of tripalmitin and tristearin and their mixing behavior with triolein. J. Am. Oil Chem. Soc. 1985, 62, 1237-1244.

(22) Ollivon, M.; Perron, R. Measurements of enthalpies and entropies of unstable crystalline forms of saturated even monoacid triglycerides. Thermochim. Acta 1982, 53, 183-194.

(23) Okada, M. The transformation of SSS crystal from $\alpha$ form to $\beta$ form by melt grown method. J. Electron Microsc. 1964, 180-181.

(24) Wesdorp, L. H. Liquid-multiple solid-phase equilibria in fats. Thesis, Technische Universiteit Delft, 1990.

(25) Miltenburg, J. C. van; Ekeren, P. J. van; Gandolfo, F. G.; Flöter, E. Investigation of the thermal behaviour of trielaidin between $10 \mathrm{~K}$ and 360 K. J. Chem. Eng. Data 2003, 48, 1245-1250.

(26) Miltenburg, J. C. van; ten Grotenhuis, E. A Thermodynamic investigation of tripalmitin. molar heat capacities of the $\alpha$ - and $\beta$-form between $10 \mathrm{~K}$ and $350 \mathrm{~K}$. J. Chem. Eng. Data 1999, 44, $721-726$.

(27) van Miltenburg, J. C.; van den Berg, G. J. K.; van Genderen, A. C. G. An adiabatic calorimeter for small samples. The solid-liquid system naphthalene-durene. Thermochim. Acta 2002, 383, 131 .

(28) van Miltenburg, J. C.; van Genderen, A. C. G.; van den Berg, G. J. K. Design improvements in adiabatic calorimetry. The heat capacity of cholesterol between 10 and $425 \mathrm{~K}$. Thermochim. Acta 1998, 319, 151-162.

(29) Perron, R.; Petit, J.; Mathieu, A. A study of palmitic-stearic triglycerides and their binary mixtures by differential thermal analysis. I-pure triglycerides. Chem. Phys. Lipids 1969, 3, 1128.

(30) Wu, X. Z.; Sirota, E. B.; Sinha, S. K.; Ocko, B. M.; Deutsch, M. Surface crystallization of liquid normal-alkanes. Phys. Rev. Lett. 1992, 70 .

Received for review March 9, 2005. Accepted May 31, 2005.

JE050092D 